\title{
Vibration feature evaluation of the motor-gear system with gear tooth crack and rotor bar error
}

Wenyu Bai ${ }^{\mathrm{ab} * 1}$, Qiang Zeng ${ }^{\mathrm{c} 1}$, Yawen Wang ${ }^{\mathrm{d}}$, Guojin Feng ${ }^{\mathrm{e}}$, Guanjun Bao ${ }^{\mathrm{a}}$

${ }^{a}$ Key Laboratory of Special Purpose Equipment and Advanced Processing Technology, Ministry of Education, Zhejiang University of Technology, Hangzhou 310023, P.R.C.

${ }^{\mathrm{b}}$ Zhejiang Jinbang Sports Equipment co., Ltd. No. 36 Juxian Road, Huzhen Town, Jinyun County, Zhejiang 321404, P.R.C.

${ }^{\mathrm{c}}$ The State Key Laboratory of Mechanical Transmission, Chongqing University, Chongqing 400030, P.R.C.

${ }^{\mathrm{d}}$ University of Texas at Arlington, Arlington, Texas 76019, USA

${ }^{\mathrm{e}}$ School of Computing and Engineering, University of Huddersfield, Huddersfield HD1 3DH, U.K.

\section{A B S T R A C T}

The high speed and high power density electromechanical system for the electric vehicle is urgently required to meet stricter emission regulation and achieve higher performance. Therefore, the electromechanical coupling effect is becoming more strengthened and may significantly degrade the performance of the motor and gear system. When gear or motor failures like gear tooth crack or rotor bar breakage are present, the operation safety of the electric vehicle would be threatened. So the exploration of the fault features for the motor-gear system is crucial for prevention of disastrous consequences. In this paper, the fault vibration features of the motor-gear system with gear root crack and motor rotor error under various excitations from both motor and gear transmission system are investigated. The electromechanical dynamic model considering the nonlinear air-gap permeance and time-varying mesh stiffness is employed, and the gear tooth root crack fault and the rotor bar breakage are integrated into the dynamic model to acquire the dynamic characteristics with faults. Then, the angular-synchronous average technique is applied to strengthen the statistical characteristics of fault vibration signal and eliminate the effect of speed variation due to the external excitation. The statistical indicators extracted from the angular-synchronous average vibration signals can reveal the progression of gear faults for the gear transmission without motor rotor error. However, the analyzed results indicate that the popular statistical indicators would fail to detect the early tooth fault when the motor rotor error is coupled.

KEYWORDS: Motor-gear System, Fault Vibration Characteristic, Nonlinear Excitations, Tooth Crack, Rotor Bar Error

\section{INTRODUCTION}

Although traditional vehicles relying primarily on internal combustion engines have been existing for a long time, electric cars are already becoming a popular choice, and promptly take a considerable share of the new car market [1]. Even for the electric vehicle, the gear system is still an indispensable part so that the motor can work in the most efficient region. Therefore, the dynamic characteristics of this electromechanical system under various condition have attracted much attention $[2,3]$. The high speed and high power density electromechanical system for the electric vehicle is urgently required as the fast development of transportation vehicle towards emission pollution reduction and high mobility. However, high power to weight ratio, faster speed and intensified electromechanical interactions could worsen the working conditions of the motor-gear system, which is more likely to lead to failures of the gear transmission system and driving motor, such as gear tooth crack or motor bar failure [4]. These failures will degrade the dynamic performance and cause destructive power interference or disastrous

\footnotetext{
${ }^{*}$ Corresponding author. E-mail address: bauyo@zjut.edu.cn (W. Bai).

${ }^{1}$ These authors contributed equally to this work.
} 
consequences [5]. To ensure safety and reliability for the electric car, it is affirmatively crucial to evaluation the dynamic performance under fault induced excitations of motor-gear system for avoiding tragedy consequences.

Numerous works in the area of fault gear system dynamics simulation and fault feature evaluation are performed. Wang et al. [6] proposed a scheme of using the resonance demodulation technique to detect the incipient gear tooth cracks through the structural resonances excited by tooth crack. G. Dalpiaz et al. [7] applied spectral correlation density and continuous wavelet transform of the time-synchronous average signal of vibration to detect gear faults. Tian et al. [8] derived the analytical expression of the position-dependent mesh stiffness of the healthy gear and tooth fault gear by using the potential energy method and the characteristics of involute gear teeth mesh stiffness. Based on Tian's model, Wu et al. [9] statistically studied the vibration signature of spur gear tooth crack in a onestage gearbox; Liang et al. [10] analytically evaluated the mesh stiffness of a planetary gear set and established a crack propagation model to quantify the mesh stiffness reduction due to the crack. S. Jia et al. [11] found that the coherent time synchronous average vibration signal can be practical in distinguishing the difference between localized tooth spalling and crack damage. Furthermore, Chen et al. [4] found that the angular-synchronous average technique can effectively expose the fault vibration feature in locomotive gear system with tooth root crack propagation compared with time-synchronous average technique. Additionally, Wang et al. [12], Ma et al. [13], Saxena et al. [14], J. Parra et al. [15] and Xue et al. [16] have also proposed their gear mesh stiffness models with tooth crack and studied the behavior of the engaged gear pair with faults.

The rotor bar failure is one of the common faults in driving motor in electric cars. The motor current signature analysis (MCSA) of the healthy motor or with broken bar has thoroughly been performed in the last decades [17]. For instance, Joksimovic [18] analyzed the existence of the rotor slot harmonics as well as saturation-related harmonics on healthy machines with different numbers of stator slots, rotor bars, and pole pairs. Elkasabgy et al. [19] proposed to insert search coils around a stator tooth tip or the stator yoke to detect the existence of the rotor bar fault. Liang et al. [20] performed a comparison study between vibration, phase current and transient rotor speed analysis in term of sensitivity to rotor faults in three-phase induction motors. Didier et al. [21] applied Hilbert transform to the line current spectrum modulus for the detection of incipient broken rotor bar without the reference of healthy motor at low load. Kaikaa et al. [22] analyzed the stator current of an induction machine operating with mixed faults, i.e. broken rotor bars and static eccentricity. Additional harmonics in the form of sidebands centered around the fundamental and slot harmonics were found due to the mixed faults. Ouadah et al. [23] analyzed the sidebands around the slot harmonics to detect the rotor error and found that the magnitude of additional components of the slot harmonics increases with the number of broken rotor bars. Hassan et al. [17] presented a survey of existing broken rotor bar fault detection techniques with new classification based on the fault signature.

The aforementioned research works provide some guidance for the fault detection in the motor or gear transmission system. However, when the gear fault and motor fault take place simultaneously, the existing fault vibration detection techniques for gear transmission system $[4,24]$ may no longer be functional because of the additional vibration components due to the motor error. Meanwhile, the works on the mixed faults related vibration characteristics and fault detection for the motor-gear system are still limited.

Therefore, this study investigates the vibration feature of the motor-gear system with gear tooth crack and rotor bar error. It is expected to guide the effective and efficient condition monitoring and early detection of the gear fault in the motor-gear electromechanical system with complicated conditions. The rest of the paper is organized as follows. In Section 2, the nonlinear dynamic model of the motor-gear system proposed in Ref. [3] is introduced, so the electromechanical system vibration responses can be obtained by dynamic simulation with the tooth root crack fault of the gear and the rotor bar breakage of the motor. The dynamic characteristics of the motor-gear system is experimentally investigated in Section 3. Based on the experimental study, the dynamic planetary gear transmission model is verified. The simulated dynamic responses are analyzed in Section 4. The angularsynchronous average technique is implemented to elucidate the vibration characteristics due to the faults, and the 
statistical indicators derived from the processed vibration signals are adopted to reveal the progression and status for the different scenarios of faults.

\section{THE ELECTROMECHANICAL DYNAMIC MODEL OF THE MOTOR-GEAR SYSTEM}

2.1. Permeance network model of the motor considering the slot effect

This section will introduce the developed permeance network dynamic model in Ref. [3] where the electromechanical dynamical characteristics of the motorgear system under different external excitations are investigated, and the permeance network dynamic motor modelling was experimentally validated as in Ref. [25]. The permeance network dynamic motor model is employed in this study to exhibit the vibration features cause by the fault gear and its development when the motor rotor bar fault is seeded.

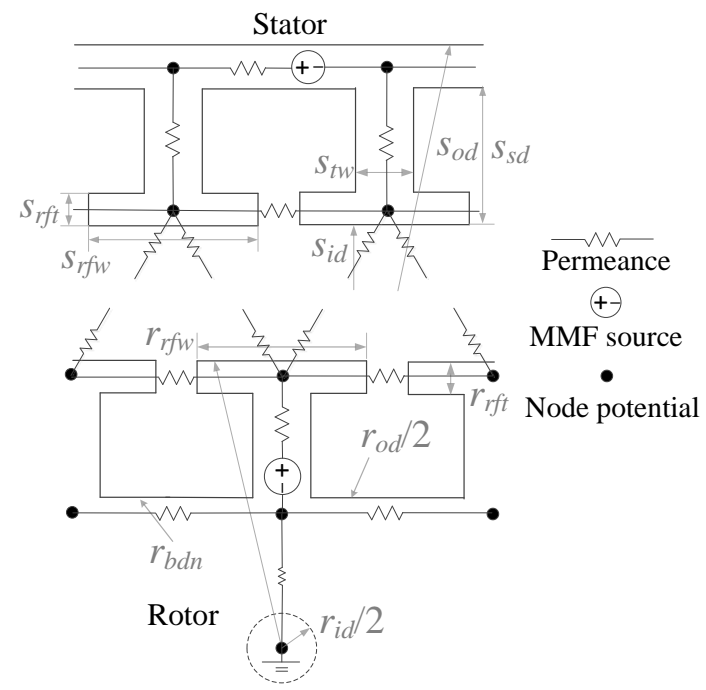

Fig. 1 Portion structure and permeance network of the motor

This permeance network dynamic model is illustrated as in figure 1, where a portion of the induction motor slotting structure and permeance network is shown. The slot effect is considered in this model as the slotting structures are among the main parameters of the motor. The value of magnetic motive force (MMF) source is directly corresponds to the slot current which can be illustrated either in the yoke or the tooth. The flux driven by the MMF includes the flux entering the stator and rotor permeance network sector as well as the leakage flux that travels outside the permeance network. The permeance network model has inputs of the stator voltage and electrical rotor position and the outputs of the stator current and electromagnetic torque, as well as the stator and rotor flux linkage as the state variables. The relationship between the voltage, current and flux can be presented as following [26],

$\left\{\begin{array}{l}p \lambda_{q d 0}=v_{q d 0}-r_{\mathrm{s}} i_{q d 0} \\ p \lambda_{\mathrm{r}, j}=-r_{\mathrm{b}, j}\left(i_{\mathrm{r}, j}-i_{\mathrm{r} j+1}\right)-r_{\mathrm{be}, j}\left(i_{\mathrm{r}, j}-i_{\mathrm{be}}\right)-r_{\mathrm{b}, j-1}\left(i_{\mathrm{r}, j}-i_{\mathrm{r}, j-1}\right)-r_{\mathrm{fe}, j}\left(i_{\mathrm{r}, j}-i_{\mathrm{fe}}\right) \\ p \lambda_{\mathrm{fe}}=-\sum_{j=1}^{N_{r s}} r_{\mathrm{fe}, j}\left(i_{\mathrm{fe}}-i_{\mathrm{r}, j}\right)\end{array}\right.$

where, the symbol $\lambda_{q d 0}, \lambda_{\mathrm{r}}, \lambda_{\mathrm{fe}}$ are the stator flux linkage, rotor flux linkage and rotor end flux linkage respectively. $i_{q d 0}, i_{\mathrm{r}}, i_{\text {be }}$ and $i_{\mathrm{fe}}$ are the stator current, rotor current, rotor bar back end current and rotor bar front end current respectively. $v_{q d 0}, r_{\mathrm{s}}, r_{\mathrm{b}}, r_{\mathrm{be}}$ and $r_{\mathrm{fe}}$ are the stator voltage, stator resistance, rotor bar resistance, rotor bar back end resistance and rotor bar front end resistance respectively.

The time-varying air gap permeance is an important internal excitation for the motor as the stator and rotor is often open slotted to increase the airgap flux density or the electromagnetic torque. It is obtained by taking into account the overlap area, air gap length and vacuum permeability between each adjacent stator and rotor tooth. The time-varying permeance between the stator tooth and rotor tooth is computed after that,

$$
\left\{\begin{array}{l}
P_{\mathrm{st}, \mathrm{rt}: i, j}=\sum_{j}^{n_{\mathrm{rt}}} a_{i, j} \times \mu_{0} / g \\
P_{\mathrm{rt}, \mathrm{st}: j, k}=\sum_{k}^{n_{\mathrm{st}}} a_{j, k} \times \mu_{0} / g
\end{array}\right.
$$

where, the symbol $P_{\text {st,rt: } i, j}$ is the tooth-to-tooth permeance with respect to the stator tooth and $P_{\mathrm{rt}, \mathrm{st}: i, j}$ is the tooth-totooth permeance with respect to the rotor tooth, as each corresponding tooth would face more than one tooth (number represented by $n_{\mathrm{st}}$ or $n_{\mathrm{rt}}$ ) from counter side. The symbol $a_{i, j}$ is the overlap area of the corresponding tooth pair, $g$ is the air gap length and the $\mu_{0}$ is the vacuum permeability.

The flux flow circle in the stator and interacts with the teeth of the rotor when it crosses the airgap between them. The relationship of the nodal potential $(M)$, MMF $(i)$ and the permeance $(A)$ for the motor can be obtained according to the magnetic field property. So the stator and rotor sector nodal equations as well as the stator flux with leakage flux and the rotor flux linkage equations are readily expressed as [26], 


$$
\left\{\begin{array}{l}
A_{\mathrm{sb}-\mathrm{sb}} M_{\mathrm{sb}}+A_{\mathrm{sb}-\mathrm{st}} M_{\mathrm{st}}+A_{\mathrm{sb}-\mathrm{si}} i_{q d 0}=0 \\
A_{\mathrm{st}-\mathrm{sb}} M_{\mathrm{sb}}+A_{\mathrm{st}-\mathrm{st}} M_{\mathrm{st}}+A_{\mathrm{st}-\mathrm{rt}} M_{\mathrm{rt}}=0 \\
A_{\mathrm{rt}-\mathrm{st}} M_{\mathrm{st}}+A_{\mathrm{rt}-\mathrm{rt}} M_{\mathrm{rt}}+A_{\mathrm{rt}-\mathrm{sb}} M_{\mathrm{rb}}+A_{\mathrm{rt}-\mathrm{ri}} i_{\mathrm{r}}=0 \\
A_{\mathrm{rb}-\mathrm{rt}} M_{\mathrm{rt}}+A_{\mathrm{rb}-\mathrm{rb}} M_{\mathrm{rb}}+A_{\mathrm{rb}-\mathrm{ri}} i_{\mathrm{r}}=0 \\
\lambda_{\mathrm{qd} 0}=A_{\mathrm{s} \lambda-\mathrm{sb}} M_{\mathrm{sb}}+A_{\mathrm{s} \lambda-\mathrm{st}} M_{\mathrm{st}}+L_{1} i_{\mathrm{qd} 0} \\
\tilde{\lambda}_{\mathrm{r}}^{\mathrm{T}}=A_{\mathrm{r} \lambda-\mathrm{rt}} M_{\mathrm{rt}}+A_{\mathrm{r} \lambda-\mathrm{rb}} M_{\mathrm{rb}}+A_{\mathrm{r} \lambda-\mathrm{ri}} i_{\mathrm{r}}
\end{array}\right.
$$

where the subscripts "sb", "st", "rt", "rb", "si", "ri", "s $\lambda$ ", " $\mathrm{\lambda} \lambda$ " denote the state base, stator tooth, rotor tooth, rotor base, stator current, rotor current, stator flux linkage, and rotor flux linkage, respectively. The symbol $L_{1}$ is the stator leakage inductance.

2.2 Lateral-torsional coupled dynamic model of the planetary gear system

In the lateral-torsional lumped-parameter model of the spur planetary gear (PG) system as shown in figure 2, the model coordinates are categorized into three types, namely (1) the static coordinate system $X Y O$, (2) moving coordinate $x y o$ system synchronously rotating with the carrier and (3) moving coordinate system $\xi_{n} \eta_{n} O_{n}(n=1,2$, $3 . . . n$ denote the $n$th planet gear) positioned at planet gear center and fixed on the carrier. The subscript $x, y, c, r, p_{n}, s$ represent the $x$-, $y$ - direction, carrier, ring gear, $n$th planet gear and sun gear respectively. Meanwhile, $k$ denotes the mesh or supporting stiffness. And $c$ denotes the corresponding dumping, which is not shown in the figure. The non-inertial coordinate system of Newton's law is adopted to in this paper to deduce the motion equations for planetary gear system. The position and motion of the components like sun gear, planet gear, ring gear or the carrier can be deduced with the values obtained in their corresponding coordinate. The acceleration of the planet gear could be presented as,

$$
\ddot{r}_{\mathrm{p}}(\mathbf{i}, \mathbf{j})=\left(\ddot{x}_{\mathrm{p}}-2 \dot{\theta}_{\mathrm{c}} \dot{y}_{\mathrm{p}}-\dot{\theta}_{\mathrm{c}}^{2} x_{\mathrm{p}}-\ddot{\theta}_{\mathrm{c}} y_{\mathrm{p}}\right) \mathbf{i}+\left(\ddot{y}_{\mathrm{p}}-2 \dot{\theta}_{\mathrm{c}} \dot{x}_{\mathrm{p}}-\dot{\theta}_{\mathrm{c}}^{2} y_{\mathrm{p}}-\ddot{\theta}_{\mathrm{c}} x_{\mathrm{p}}\right) \mathbf{j}
$$

where, the symbols $2 \dot{\theta}_{\mathrm{c}} \dot{y}_{\mathrm{p}}$ and $2 \dot{\theta}_{\mathrm{c}} \dot{x}_{\mathrm{p}}$ are the Coriolis accelerations, $\dot{\theta}_{\mathrm{c}}^{2} x_{\mathrm{p}}$ and $\dot{\theta}_{\mathrm{c}}^{2} y_{\mathrm{p}}$ are the centripetal accelerations. The motion equation for the planet gear could be summarized as,

$$
\left\{\begin{array}{l}
m_{\mathrm{p}} \ddot{r}_{\mathrm{p}}(\boldsymbol{i}, \boldsymbol{j})=\boldsymbol{F}_{\mathrm{m}}(\boldsymbol{i}, \boldsymbol{j})+\boldsymbol{F}_{t}(\boldsymbol{i}, \boldsymbol{j}) \\
i_{\mathrm{p}} \ddot{\theta}_{\mathrm{p}}(\boldsymbol{k})=\boldsymbol{F}_{\mathrm{m}}(\boldsymbol{k}) l(\boldsymbol{k})
\end{array}\right.
$$

where the symbol $m_{\mathrm{p}}$ and $i_{\mathrm{p}}$ are the inertia mass and moment inertia respectively, $\boldsymbol{i}$ and $\boldsymbol{j}$ are the unit vector of $x y o$ coordinate system, $\boldsymbol{k}$ is the unite vector in the rotation direction vertical to the xyo coordinate. $\boldsymbol{F}_{\mathrm{m}}(\boldsymbol{i}, \boldsymbol{j}, \boldsymbol{k}), \boldsymbol{F}_{t}(\boldsymbol{i}, \boldsymbol{j})$ is the planet gear mesh force and the support force accompanied with dumping force converted in $\boldsymbol{i}, \boldsymbol{j}$ and $\boldsymbol{k}$ direction respectively. The symbol $l(\boldsymbol{k})$ is the moment arm of the mesh force for the planet and $\theta_{\mathrm{p}}$ is the rotation angle of the planet in $\xi_{n} \eta_{n} o_{n}$ coordinate system. Meanwhile, the motion equations for sun gear, carrier and ring gear can be deduced similarly except that the additional external torques acting on the corresponding component in $\boldsymbol{k}$ direction like the electromechanical torque acting on sun gear, load torque acting on the carrier and torsional moment acting on ring gear from the housing.

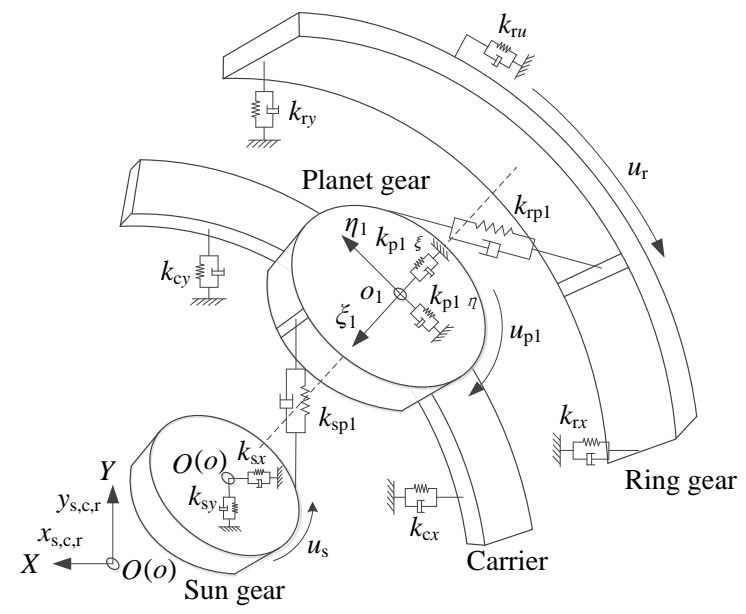

Fig. 2 Structure and modelling of the planetary gear system

The gear mesh stiffness is calculated in this study with the potential energy method by regarding the gear tooth as a cantilever beam with a changing cross-section. Based on elastic mechanics, the single tooth pair mesh stiffness is composed of the Hertzian contact stiffness $K_{\mathrm{h}}$, bending stiffness $K_{\mathrm{b}}$, shear stiffness $K_{\mathrm{s}}$, axial compressive stiffness $K_{\mathrm{a}}$, fillet foundation stiffness $K_{\mathrm{f}}$. The $j$ th tooth pair mesh stiffness can be calculated as,

$$
K_{j}=\left(1 / K_{\mathrm{h}}+1 / K_{\mathrm{f}}+\sum_{i=1}^{2}\left(1 / K_{\mathrm{b} i}+1 / K_{\mathrm{s} i}+1 / K_{\mathrm{a} i}\right)\right)^{-1}
$$

The total mesh stiffness for multi-tooth meshing gear pair can be pressed as [27],

$$
K_{\text {total }}=\sum_{j=1}^{n} K_{j} /\left(1+\sum_{j=1}^{n} K_{j} E_{i j} / F\right)
$$

where the symbol $E_{i j}$ is the spacing error, $n$ is the number of engaged tooth pair, $F$ is the external force in the line of action. And more detail explanation for mesh stiffness calculation can be found in Ref. [27].

The coupling relationship between the driving motor and planetary gear system is achieved by using the shaft section, therefore, the force and movement interactions between 
them can be obtained by the equations as following,

$$
\left\{\begin{array}{c}
j \ddot{\theta}_{\mathrm{m}}=T_{\mathrm{e}}-T_{\mathrm{sh}} \\
T_{\mathrm{sh}}=k_{\mathrm{sh}} \Delta \theta+c_{\mathrm{sh}} \Delta \dot{\theta}
\end{array}\right.
$$

where, the symbols $T_{\mathrm{e}}$ and $T_{\mathrm{sh}}$ are the torques from motor and shaft, respectively. $k_{\mathrm{sh}}$ and $c_{\mathrm{sh}}$ are the torsional stiffness and damping of the shaft. $\Delta \theta=\theta_{\mathrm{m}}-\left(\theta_{\mathrm{s}}+\theta_{\mathrm{c}}\right), \theta_{\mathrm{m}}$ is the angular displacement of the motor.

The signals from the experiment and simulation are processed by the angular-synchronous average technique to remove the adverse effect from speed fluctuations. Then the processed data can be resampled in time domain with mean value of the motor speed. Thus, the difference signals will be computed by filtering of the mesh frequency and its harmonics, which can be applied in the section 4 . However, the historic signals of the actual system have to be prepared to perform the analysis of the variation trend between the fault degree and the statistical index.

\section{EXPERIMENTAL STUDIES OF THE MOTOR-} GEAR TRANSMISSION SYSTEM DYNAMIC FEATURES

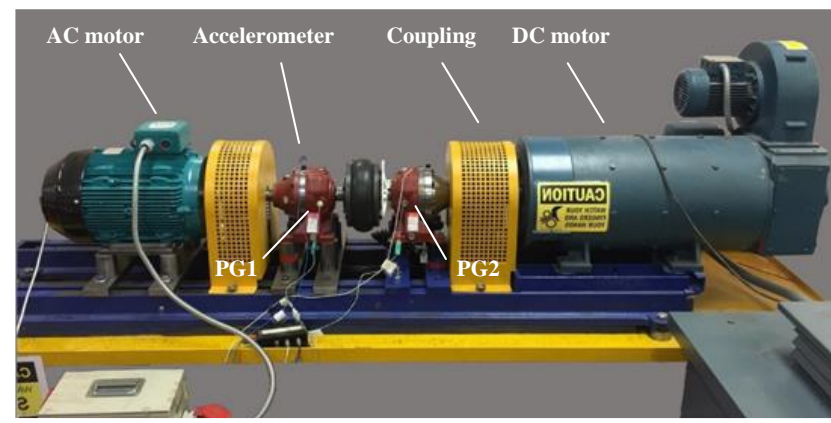

Fig. 3 Induction motor and planetary gear test rig

The induction motor connected the planetary gear system with flexible coupling is shown in figure 3 , which is primitively built to verify the dual detector IAS (Instantaneous Angular Speed) based diagnosing method of gear faults such as partially broken sun gear or planet gear tooth in the PG2 $[28,29]$. The test rig is driven by an $11 \mathrm{~kW}$ $\mathrm{AC}$ motor (Brook Crompton) and the power is transmitted to the $85 \mathrm{~kW}$ DC generator (STM power transmission Ltd.) by the back to back installed planetary gear boxes with transmission ration of 5.77 (PG1) and 7.2 (PG2) respectively. The optical dual detector encoders are installed on both sides of the PG2, and the vibration of the PG1 is dumped by the rubber coupling in the middle of the PG1 and the PG2. Therefore the IAS signals from PG2 side is not adopted. It is attached here for the experimental study and verification of the dynamic planetary gear model for PG1 and dynamic characteristic of the motor-gear system at comprehensive fault conditions. To some extent, the dynamic motor model would be verified when the features obtained along with the experimental results are in accord with empirical equations. The parameters of the PG1 are shown in table 1.

Table 1 Main parameters for the PG1

\begin{tabular}{c|c|c|c}
\hline Max. input speed $(\mathrm{rpm})$ & 2800 & Sun teeth No. $\left(Z_{\mathrm{s}}\right)$ & 13 \\
\hline Ring teeth No. $\left(Z_{\mathrm{r}}\right)$ & 62 & Gear ratio & 5.77 \\
\hline 4x Planets teeth No. $\left(Z_{\mathrm{p}}\right)$ & 24 & Power $(\mathrm{kW})$ & 35.07 \\
\hline
\end{tabular}

Table 2 Main parameters of the AC motor

\begin{tabular}{c|c|c|c}
\hline Phase No. & 3 & Rated speed $(\mathrm{rpm})$ & 1465 @ full Load \\
\hline Poles No. $(P)$ & 4 & Winding & Y star to $\Delta$ delta \\
\hline Rated power $(\mathrm{W})$ & $11 \mathrm{k}$ & Stator slots No. $(S)$ & 48 \\
\hline Rated voltage $(\mathrm{V})$ & 415 & Rotor slots No. $(R)$ & 40 \\
\hline
\end{tabular}

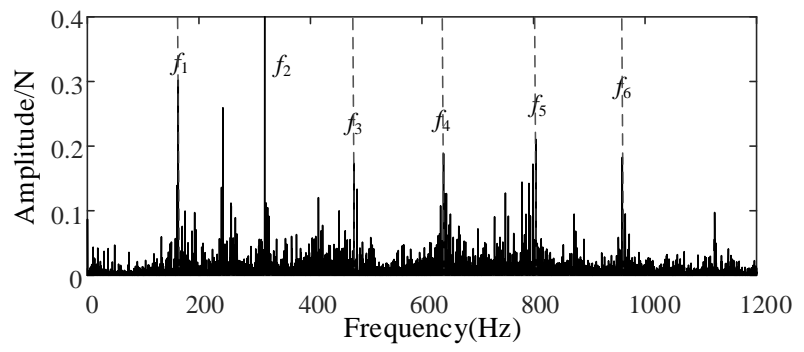

Fig. 4 The PG1 vibration spectrum

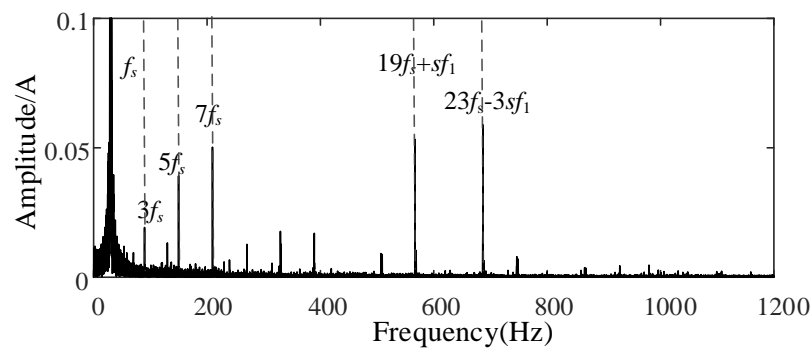

Fig. 5 The AC motor current signal spectrum

As shown in figure 4, the vibration signal spectrum of the PG1 has distinct amplitudes related to the mesh frequency and its harmonic frequencies. The dominating frequencies locate at $162.9 \mathrm{~Hz}, 318 \mathrm{~Hz}, 478.3 \mathrm{~Hz}, 638.6 \mathrm{~Hz}$, $804.1 \mathrm{~Hz}$ and $959.2 \mathrm{~Hz}$. The gear mesh frequency of sunplanet $f_{\mathrm{s} \text {-p }}$ and the planet-ring $f_{\mathrm{p} \text {-r }}$ gear pair would be obtained with the equation as following,

$$
f_{\mathrm{s}-\mathrm{p}}=f_{\mathrm{p}-\mathrm{r}}=\omega_{\mathrm{s}} Z_{\mathrm{r}} Z_{\mathrm{s}} /\left(Z_{\mathrm{r}}+Z_{\mathrm{s}}\right)
$$

where the sun gear rotation frequency $\omega_{\mathrm{s}}$ is the same as the rotation frequency of the $\mathrm{AC}$ motor. For the driving $\mathrm{AC}$ motor rotating at about $14.911 \mathrm{~Hz}$, the sun-planet gear pair 
mesh frequency $f_{\mathrm{s}-\mathrm{p}}$ are about $160.2 \mathrm{~Hz}$. And the carrier and planet rotation frequency can be calculated by equations following,

$$
\left\{\begin{array}{l}
\omega_{\mathrm{c}}=\omega_{\mathrm{s}} Z_{\mathrm{s}} /\left(Z_{\mathrm{r}}+Z_{\mathrm{s}}\right) \\
\omega_{\mathrm{p}}=\omega_{\mathrm{s}} Z_{\mathrm{s}}\left(Z_{\mathrm{p}}-Z_{\mathrm{r}}\right) / Z_{\mathrm{p}}\left(Z_{\mathrm{r}}+Z_{\mathrm{s}}\right)
\end{array}\right.
$$

Therefore, the dominating frequencies shown above in figure 4 are the modulated frequencies between mesh frequencies and rotation frequencies of the components due to amplitude modulation and frequency modulation (AM and FM) effects, which is consistent with theoretical studies in the Ref. [30, 31].

For the current of the $\mathrm{AC}$ motor, the main frequencies shown in figure 5 are frequency harmonics of the rotation speed of the rotor for the $\mathrm{AC}$ motor whose main parameters are shown in table 2 . The $1^{\text {st }}$ to $7^{\text {th }}$ harmonics are the current harmonics related to the rotor speed $f_{\mathrm{r}}$, the pole number $P$ and the slip ratio $s$ [32],

$$
f_{\mathrm{h}}=f_{s}(2 k-1)(k=1,2,3, \ldots)
$$

where $f_{s}=f_{1}(1-s)$, the symbol $f_{1}$ is the supply power frequency. However, the $19^{\text {th }}$ and $23^{\text {rd }}$ harmonics are the current harmonics associated with the rotor slots number $R$ in addition to the rotor speed and the pole number, which are the principle slot frequency $f_{\text {slot }}$ and the saturation related frequency $f_{\text {satu }}$ respectively [32],

$$
\left\{\begin{array}{l}
f_{\text {slot }}=2 k R f_{s} / P \pm f_{1} \\
f_{\text {satu }}=2 k R f_{s} / P \pm 3 f_{1}
\end{array} \quad(k=1,2,3, \ldots)\right.
$$

With the rotor and stator slot combination of $40 / 48$ for the $\mathrm{AC}$ in this experimental study, the current power spectrum density would only show the lower slot principle harmonic and upper saturation related harmonic frequency which agrees with theoretical analysis in Ref. [33].

\section{THEORETICAL ANALYSIS OF THE DYNAMIC CHARACTERISTICS FOR THE MOTOR-GEAR SYSTEM WITH FAULTS}

In this study, the AC motor is working with $35 \%$ load under a similar speed (under power supply of $30 \mathrm{~Hz}$ ) with that of experimental operation. The main design parameters of the addendum corrected gear transmission system adopted is the same with the PG1 in the experimental rig as shown in table 1. Meanwhile, the motor parameters can be found in Ref. [3] which is different from the motor in the experiment as its details of the structure are not available. It can be seen that frequencies of the sun-planet gear mesh force has the evident peaks which is marked with the mesh frequency $f_{\mathrm{m}}$ and its harmonics as shown in figure 6 and figure 7. This feature agrees with the vibration characteristics of the PG1 in the experiment. However, there is additional frequency peak on the right side of the second mesh harmonic, which is the electromagnetic predominant torque harmonic ( $\mathrm{PTH} i$ ) caused by the slot effect of the motor. The features of the PTH $i$ are shown in figure 9 and the PTH $i$ are part of the torque harmonics, the torque harmonics are summarized as [34],

$$
f_{\mathrm{T}}=3 P f_{\mathrm{r}} k(k=1,2,3, \ldots)
$$

The main frequency in motor phase current spectrum as shown in figure 8 is about the power frequency, the rest evident frequencies are the principle slot frequencies and the stator harmonics that coincide with the equation (10)(11).

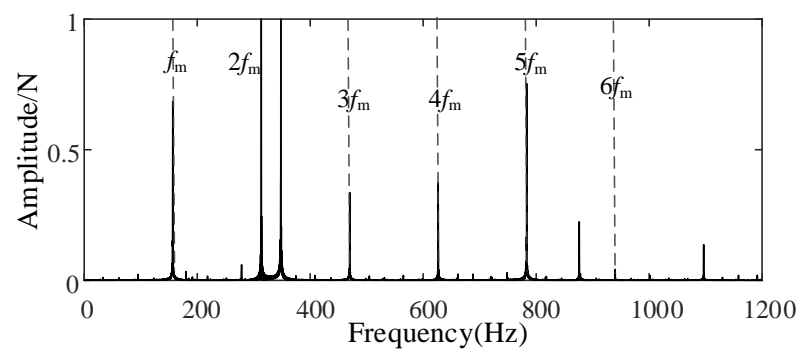

Fig. 6 Mesh force spectrum coupled with motor

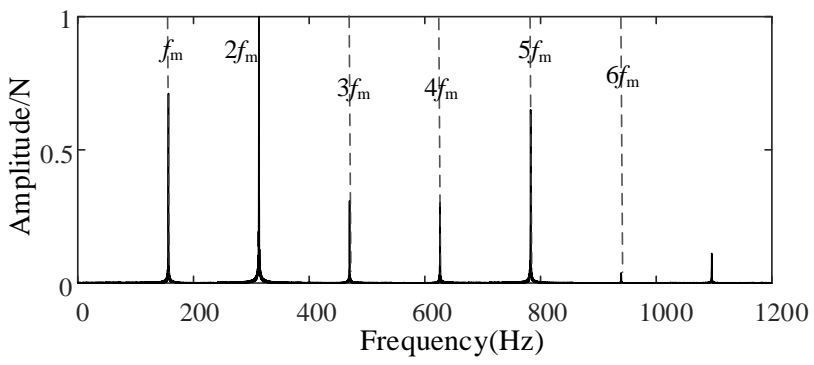

Fig. 7 Mesh force spectrum decoupled with motor

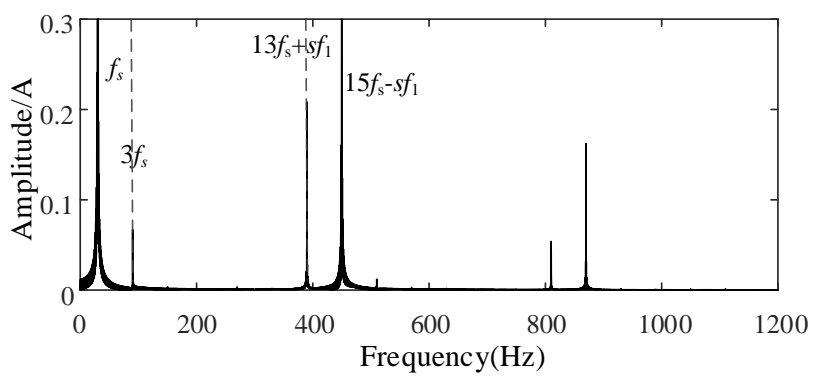

Fig. 8 The healthy motor stator current spectrum 


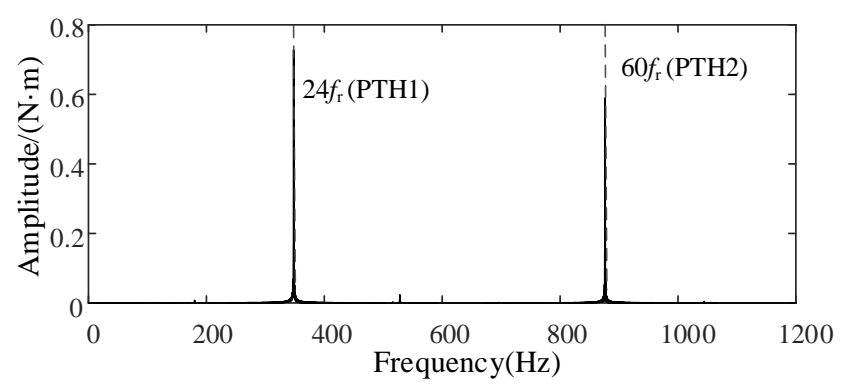

Fig. 9 The healthy motor torque spectrum

When a crack is generated on the gear tooth root, the mesh stiffness will be reduced due to the decline in the tooth effective cross section. The mesh stiffness of a sunplaner gear pair with different crack level is calculated in this paper and the results are shown in figure 10. The crack level is determined by the ratio of the effective crack length to tooth width, the effective crack length is the actual crack length projected on the tooth width at the root. The flexible deformation of the engaged gear teeth will increase because of the planet tooth root crack. Thus the mesh stiffness will decrease when the cracked tooth comes into engaging area. The more damage of the tooth root the bigger reduction of mesh stiffness it will cause.

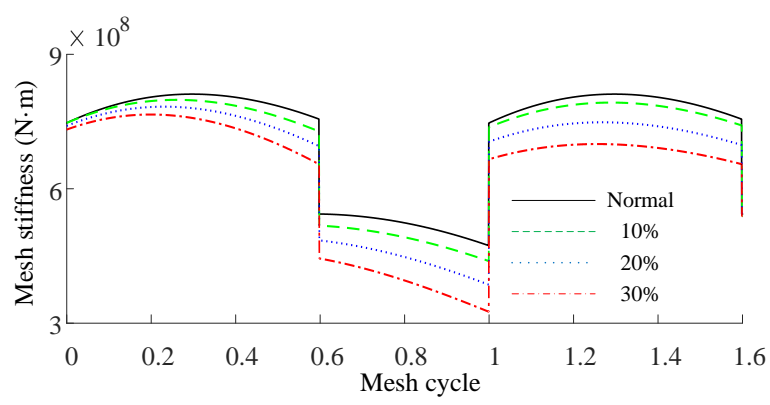

Fig.10 Mesh stiffness with different crack levels

When the planet gear tooth root bears a crack, an extra excitation due to this crack will be caused to the gear dynamic features. The dynamic mesh force with and without tooth crack ( $75 \%$ crack level) in time domain are presented in figure 11 and 12. It is observed that the periodic impulses appear in the time histories, and the impulse amplitude of the cracked case can reach as high as five times the amplitude of mesh force peak for the normal gear-pair, and the two impulses time duration is equal to the fault planet gear rotation period.

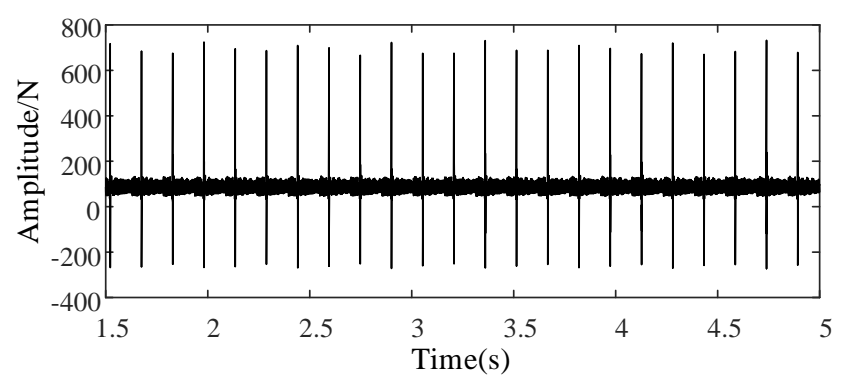

Fig.11 Mesh force with tooth fault coupled with motor

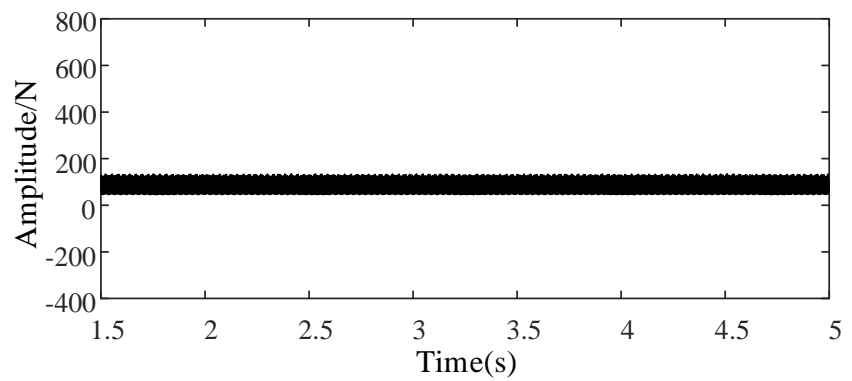

Fig.12 Healthy gear mesh force coupled with motor

The induction motor can be subjected to different operation conditions, which can cause electrical or mechanical damages on the stator or the rotor. The motor errors, such as the rotor bar breakage are common machine failures in industrial applications [23]. A motor error, namely, one rotor bar broken is implanted in the dynamic motor model, it brings speed drops and periodical fluctuations to the system as shown in figure 13. Due to the non-stationary operating condition, it usually has frequency aliasing and complicate frequency modulation. Therefore, an angular-synchronous average process is adopted to eliminate the undesirable effect of the speed transient fluctuations. It needs to be noticed that the variation of the motor speed is relatively small when compared with some circumstances such as the frequent operation conditions of speed-up or braking for the electric vehicles where the motor speed varies within a larger region.

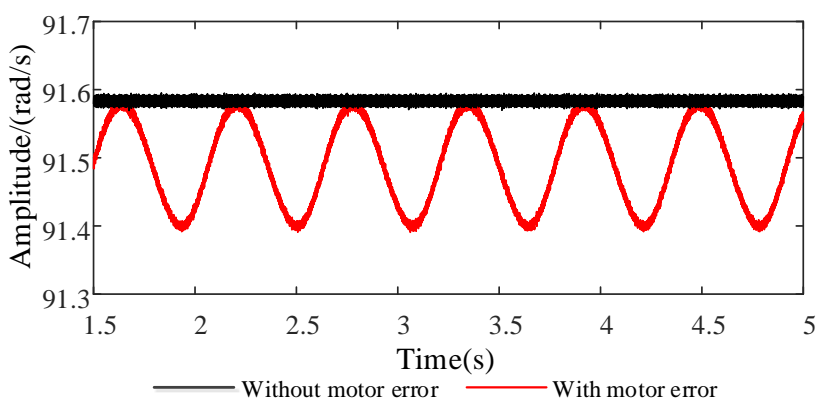

Fig.13 Motor speed with and without error 


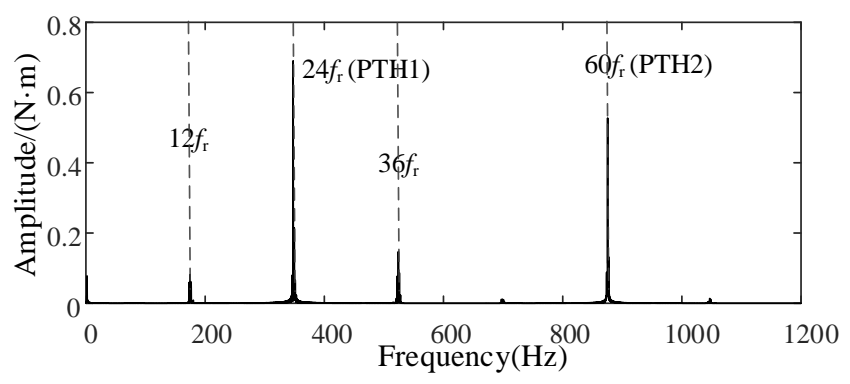

Fig.14 The false motor torque spectrum

In addition to the rotor speed drop and fluctuations, the extra electromagnet torque appears with harmonic components such as $12 f_{\mathrm{r}}$ and $36 f_{\mathrm{r}}$, which are the most distinct new peaks shown in figure 14. From the sun-planet gear mesh force frequency spectrum with root crack seeded in the planet as in figure 15, the sidebands appear near the zero frequency, second and fifth mesh harmonics. The sidebands are spaced with the rotation frequency of the fault planet gear $\omega_{\mathrm{p}}$. The predominant electromagnetic torque harmonic frequencies appear beside the second mesh harmonic and the sixth mesh harmonic, which can be seen in figure 15.

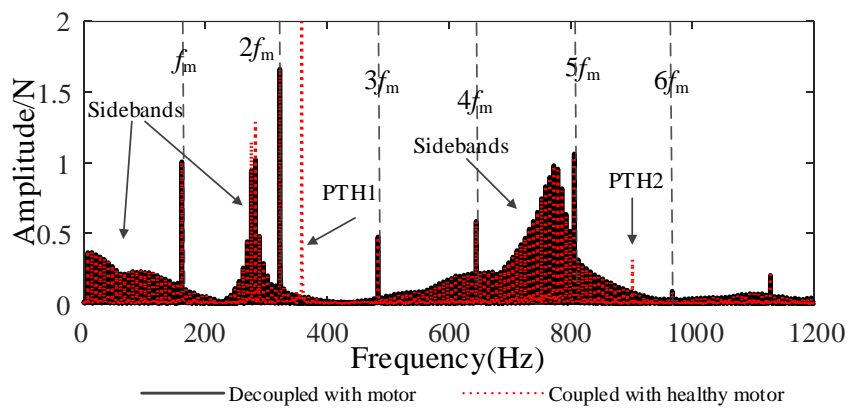

Fig. 15 The false gear mesh force spectrum coupled or decoupled with healthy motor

When gear transmission system is coupled with motor, the vibration features of the gear transmission system would be affected by this additional electromagnetic torque harmonics, severer vibrations would be triggered as the sidebands beside the second mesh harmonic are larger than the motor decoupled gear transmission system, as are presented in figure 15. The extra harmonic frequencies due to the rotor bar breakage cause the lots of additional frequencies such as the sliding frequency near the zero frequency and the torque harmonic frequency of $12 f_{\mathrm{r}}$ with sliding frequency sidebands as shown in figure16, and figure 17 illustrated the zoom of section ' $a$ ' in figure 16 .

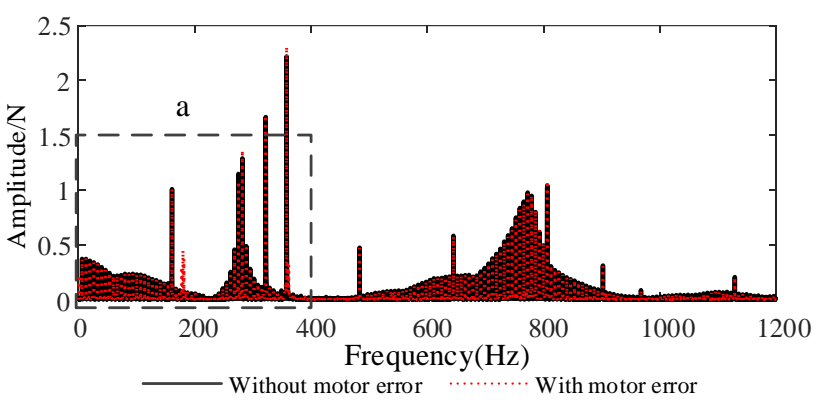

Fig.16 The false gear mesh force spectrum

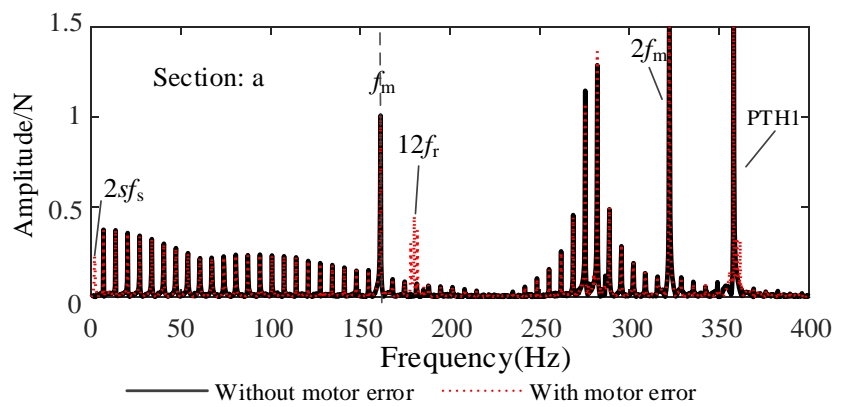

Fig.17 The false gear mesh force spectrum

As one of the most popular statistical measurements of vibration energy, the Kurtosis increase because of the shaper peaks due to the damage propagation resulted mesh force in the gear transmission. Another statistic indicator named M6A is expected to be more sensitive to peaks due to the fault in the difference signal by using of the sixth statistical moment, which is normalized by the cube of the variance [35]. Meantime, the FM4 has non-dimensional of the fourth statistical moment about the mean by the square of the variance of the difference signal. All of them are expected able to detect the faults for the motor-gear transmission system. Their equations are as following [36],

$$
\left\{\begin{array}{c}
\text { Kurtosis }=N \sum_{i=1}^{N}(S-\bar{S})^{4} /\left[\sum_{i=1}^{N}(S-\bar{S})^{2}\right]^{2} \\
\mathrm{M} 6 \mathrm{~A}=N^{2} \sum_{i=1}^{N}(d-\bar{d})^{6} /\left[\sum_{i=1}^{N}(d-\bar{d})^{2}\right]^{3} \\
\mathrm{FM} 4=N \sum_{i=1}^{N}(d-\bar{d})^{4} /\left[\sum_{i=1}^{N}(d-\bar{d})^{2}\right]^{2}
\end{array}\right.
$$

where the symbol $d$ is the difference signal, which is the resultant signal after the mesh frequency and its harmonics are removed, $\bar{d}$ is the mean value of the difference signal, $i$ is the data sequence number in the record and $N$ is the data length of the signal $S$.

For demonstrating the severity of vibration due to the fault, the increase ratio (IRatio) is defined as [4],

$$
\text { IRatio }=\left(X_{i}-X_{0}\right) / X_{0} \times 100 \%
$$

where the symbol $X_{i}, X_{0}$ denote the statistic indicator under fault condition and healthy condition respectively. 
As in table 3, the FM4 and M6A have a noteworthy increase because of the gear root crack propagation. The $25 \%$ gear root crack level with motor rotor error (one rotor bar breakage) case (b1g25) has a larger indicator value than healthy gear with healthy motor case ( $\mathrm{b} 0 \mathrm{~g} 0)$. The $75 \%$ gear root crack with motor rotor error case (b1g75) has the largest indicator amplitude. The M6A would be considered as the best indicator as the IRatio reflecting the fault is the largest compared with the FM4 and Kurtosis. At the same time, the Kurtosis almost fails to reflect the fault as its IRatio for the b1g0 case and b1g25 case are almost identical.

It should be noted that these statistic indicators fail to detect the small gear fault combined with the motor rotor error, i.e., the case of $\mathrm{b} 1 \mathrm{~g} 0$ and $\mathrm{b} 0 \mathrm{~g} 25$ as shown in table 4. The IRatio of the M6A for the cases above are very close, and it is larger for the case of $\mathrm{b} 1 \mathrm{~g} 0$ than for the $\mathrm{b} 0 \mathrm{~g} 25$ case. Meanwhile, the gaps of the IRatio for these two cases are even greater for the Kurtosis and FM4. These statistic indicators are unable to reflect the fault growth development when it is coupled with motor error, the very reason for the incompetence is that the error related motor torque harmonics cause distortion vibrations due to the electromechanical coupling effect.

The fault vibration feature of the gear transmission system decoupled with motor is also investigated as shown in table 5. The M6A and FM4 both have good performances of evaluation the fault growth when the motor is decoupled, which has been reported in Ref. [37]. What's more, the Kurtosis is the least efficient indicator among them for the gear fault detection with 25\% fault level case (g25).

Table 3 Statistical indicators versus mixed faults

\begin{tabular}{|l|cccc|}
\hline & b0g0 & b1g0 & b1g25 & b1g75 \\
\hline FM4 & 1.60 & 1.77 & 1.88 & 46.86 \\
IRatio & $0.00 \%$ & $10.94 \%$ & $17.66 \%$ & $2832.36 \%$ \\
\hline M6A & 3.01 & 3.96 & 4.95 & 4884.70 \\
IRatio & $0.00 \%$ & $31.91 \%$ & $64.78 \%$ & $162441.59 \%$ \\
\hline Kurtosis & 4.96 & 5.14 & 5.15 & 58.43 \\
IRatio & $0.00 \%$ & $3.74 \%$ & $3.89 \%$ & $1078.44 \%$ \\
\hline
\end{tabular}

Table 4 Statistical indicators versus gear fault coupled with motor

\begin{tabular}{|l|cccc|}
\hline & b0g0 & b1g0 & b0g25 & b0g75 \\
\hline FM4 & 1.60 & 1.77 & 1.70 & 46.92 \\
IRatio & $0.00 \%$ & $10.94 \%$ & $6.22 \%$ & $2836.20 \%$ \\
\hline M6A & 3.01 & 3.96 & 3.86 & 4913.40 \\
IRatio & $0.00 \%$ & $31.91 \%$ & $28.60 \%$ & $163396.61 \%$ \\
\hline Kurtosis & 4.96 & 5.14 & 4.96 & 59.29 \\
IRatio & $0.00 \%$ & $3.74 \%$ & $0.12 \%$ & $1095.77 \%$ \\
\hline
\end{tabular}

Table 5 Statistical indicators versus gear fault decoupled with motor

\begin{tabular}{|l|ccc|}
\hline & $\mathrm{g} 0$ & $\mathrm{~g} 25$ & $\mathrm{~g} 75$ \\
\hline FM4 & 12.34 & 33.54 & 55.13 \\
IRatio & $0.00 \%$ & $171.70 \%$ & $346.61 \%$ \\
\hline M6A & 485.34 & 2718.70 & 6237.50 \\
IRatio & $0.00 \%$ & $460.16 \%$ & $1185.18 \%$ \\
\hline Kurtosis & 6.09 & 6.11 & 65.64 \\
IRatio & $0.00 \%$ & $0.27 \%$ & $977.63 \%$ \\
\hline
\end{tabular}

\section{CONCLUSIONS}

In this paper, the electromechanical system dynamics is analyzed, the model of which includes a dynamic permeance network motor model and a lateral-torsional dynamic model of the planetary gear transmission system. Both of the time-varying mesh stiffness and slot effect are the major excitations to the vibration feature of the system. Then the signal processing technique is proposed by combining the angular-synchronous average technique and statistical indicator calculated from the processed signals extracted from the dynamic response features.

The planetary gear dynamics is simulated and validated with the experimental results by comparing the vibration spectrum. Then a tooth root crack is seeded in the planet gear, and a rotor bar breakage is introduced in the motor. The dynamic responses of the comprehensive faults are investigated by the statistical indicator with the proposed signal process technique which eliminates the adverse effect from speed fluctuations. The results indicate that the motor rotor error related motor torque harmonics distorted the vibrations of the gear transmission system, which causes the selected statistical indicators to fail to detect the small tooth root crack when the motor fault is coupled.

The motor rotor error of the electromechanical system causing additional vibrations which not only leads to the degradation of the system's performance and reliability but also triggers false alarm of the gear transmission condition monitoring. Therefore, based on the fault study of the system dynamics, it is advised to inspect the existence of 
the faults from the motor side when performing condition monitoring of the gear transmission system. In addition, the rotor eccentricities and the gear vibration transfer path effect can also affect the condition monitoring of the motorgear system, and will be further studied as a next step.

\section{ACKNOWLEDGMENT}

This study is funded by the Key Research and Development Program of Zhejiang Province, P. R. China (Grant No. 2020C01150), and the authors are also thankful for the advice and recommendation of the reviewers and editors.

\section{CONFLICT OF INTEREST}

The authors declare that they have no conflict of interest.

\section{REFERENCES}

[1] M. Horn, J. MacLeod, M. Liu, J. Webb, N. Motta, Supercapacitors: A new source of power for electric cars?, Econ Anal Policy, 61 (2019) 93-103.

[2] F. Wang, J. Zhang, X. Xu, Y.F. Cai, Z.G. Zhou, X.Q. Sun, New teeth surface and back (TSB) modification method for transient torsional vibration suppression of planetary gear powertrain for an electric vehicle, Mechanism and Machine Theory, 140 (2019) 520-537.

[3] W. Bai, D. Qin, Y. Wang, T.C. Lim, Dynamic characteristics of motor-gear system under load saltations and voltage transients, Mechanical Systems and Signal Processing, 100C (2018) 1-16.

[4] Z.G. Chen, W.M. Zhai, K.Y. Wang, Vibration feature evolution of locomotive with tooth root crack propagation of gear transmission system, Mechanical Systems and Signal Processing, 115 (2019) 29-44.

[5] X.H. Jin, F.Z. Cheng, Y.Y. Peng, W. Qiao, L.Y. Qu, Drivetrain Gearbox Fault Diagnosis VIBRATION- AND CURRENT-BASED APPROACHES, Ieee Ind Appl Mag, 24 (2018) 56-66.

[6] W. Wang, Early detection of gear tooth cracking using the resonance demodulation technique, Mechanical Systems and Signal Processing, 15 (2001) 887-903.

[7] G. Dalpiaz, A. Rivola, R. Rubini, Effectiveness and sensitivity of vibration processing techniques for local fault detection in gears, Mechanical systems and signal processing, 14 (2000) 387-412.

[8] X. Tian, Dynamic simulation for system response of gearbox including localized gear faults, University of Alberta Edmonton,, Alberta, Canada, 2004. [9] S. Wu, M.J. Zuo, A. Parey, Simulation of spur gear dynamics and estimation of fault growth, Journal of Sound and Vibration, 317 (2008) 608624.

[10] X. Liang, M.J. Zuo, M. Pandey, Analytically evaluating the influence of crack on the mesh stiffness of a planetary gear set, Mechanism and Machine Theory, 76 (2014) 20-38.
[11] S. Jia, I. Howard, Comparison of localised spalling and crack damage from dynamic modelling of spur gear vibrations, Mechanical Systems and Signal Processing, 20 (2006) 332-349.

[12] Z. Wan, H. Cao, Y. Zi, W. He, Z. He, An improved time-varying mesh stiffness algorithm and dynamic modeling of gear-rotor system with tooth root crack, Engineering Failure Analysis, 42 (2014) 157-177.

[13] H. Ma, X. Pang, R. Feng, J. Zeng, B. Wen, Improved time-varying mesh stiffness model of cracked spur gears, Engineering Failure Analysis, 55 (2015) 271-287.

[14] A. Saxena, A. Parey, M. Chouksey, Time varying mesh stiffness calculation of spur gear pair considering sliding friction and spalling defects, Engineering Failure Analysis, 70 (2016) 200-211.

[15] J. Parra, C.M. Vicuña, Two methods for modeling vibrations of planetary gearboxes including faults: Comparison and validation, Mechanical Systems and Signal Processing, 92 (2017) 213-225.

[16] S. Xue, I. Howard, Torsional vibration signal analysis as a diagnostic tool for planetary gear fault detection, Mechanical Systems and Signal Processing, 100 (2018) 706-728.

[17] O.E. Hassan, M. Amer, A.K. Abdelsalam, B.W. Williams, Induction motor broken rotor bar fault detection techniques based on fault signature analysis - a review, Iet Electr Power App, 12 (2018) 895-907.

[18] G.M. Joksimovic, J. Riger, T.M. Wolbank, N. Peric, M. Vasak, StatorCurrent Spectrum Signature of Healthy Cage Rotor Induction Machines, Ieee Transactions on Industrial Electronics, 60 (2013) 4025-4033.

[19] N.M. Elkasabgy, A.R. Eastham, G.E. Dawson, Detection of broken bars in the cage rotor on an induction machine, IEEE transactions on industry applications, 28 (1992) 165-171.

[20] B. Liang, S.D. Iwnicki, A.D. Ball, Asymmetrical stator and rotor faulty detection using vibration, phase current and transient speed analysis, Mechanical systems and signal processing, 17 (2003) 857-869.

[21] G. Didier, E. Ternisien, O. Caspary, H. Razik, A new approach to detect broken rotor bars in induction machines by current spectrum analysis, Mechanical Systems and Signal Processing, 21 (2007) 1127-1142.

[22] M.Y. Kaikaa, M. Hadjami, A. Khezzar, Effects of the simultaneous presence of static eccentricity and broken rotor bars on the stator current of induction machine, IEEE Transactions on Industrial Electronics, 61 (2014) 2452-2463.

[23] M. Ouadah, O. Touhami, R. Ibtiouen, Improvement of the detection of the defect squirrel cage rotor by the study of additional components of the space harmonics, Electr Eng, 100 (2018) 2485-2497.

[24] V. Sharma, A. Parey, A review of gear fault diagnosis using various condition indicators, Procedia Engineer, 144 (2016) 253-263.

[25] B. Asghari, V. Dinavahi, Experimental validation of a geometrical nonlinear permeance network based real-time induction machine model, Power and Energy Society General Meeting, 2012 IEEE, IEEE, 2012, pp. 1- 
[26] S.D. Sudhoff, B.T. Kuhn, K.A. Corzine, B.T. Branecky, Magnetic Equivalent Circuit Modeling of Induction Motors, IEEE Transactions on Energy Conversion, 22 (2007) 259-270.

[27] Z. Chen, W. Zhai, Y. Shao, K. Wang, G. Sun, Analytical model for mesh stiffness calculation of spur gear pair with non-uniformly distributed tooth root crack, Engineering Failure Analysis, (2016) S1350630716302771.

[28] Q. Zeng, G.J. Feng, Y.M. Shao, F.S. Gu, A.D. Ball, Planetary Gear Fault Diagnosis Based on An Instantaneous Angular Speed Measurement System With a Dual Detector Setup, Ieee Access, 8 (2020) 66228-66242.

[29] Q. Zeng, G.J. Feng, Y.M. Shao, J. Devitt, F.S. Gu, A. Ball, An accurate instantaneous angular speed estimation method based on a dual detector setup, Mechanical Systems and Signal Processing, 140 (2020).

[30] Z. Feng, M.J. Zuo, Fault diagnosis of planetary gearboxes via torsional vibration signal analysis, Mechanical Systems and Signal Processing, 36 (2013) 401-421.

[31] Z.P. Feng, M.J. Zuo, Vibration signal models for fault diagnosis of planetary gearboxes, Journal of Sound and Vibration, 331 (2012) 4919-4939. [32] W.Y. Bai, D.T. Qin, Y.W. Wang, T.C. Lim, Dynamic characteristic of electromechanical coupling effects in motor-gear system, Journal of Sound and Vibration, 423 (2018) 50-64.

[33] G.M. Joksimović, J. Riger, T.M. Wolbank, N. Perić, M. Vašak, Statorcurrent spectrum signature of healthy cage rotor induction machines, IEEE Transactions on Industrial Electronics, 60 (2013) 4025-4033.

[34] K.N. Gyftakis, S.B. Lee, J. Kappatou, J.A. Antonino-Daviu, Identification of the Broken Bar Fault in Induction Motors with Rotor Air Ducts Through the Torque Spectrum, 2014 International Conference on Electrical Machines (Icem), (2014) 1614-1620.

[35] P.D. Samuel, D.J. Pines, A review of vibration-based techniques for helicopter transmission diagnostics, Journal of Sound \& Vibration, 282 (2005) 475-508.

[36] H.J. Decker, D.G. Lewicki, Spiral Bevel Pinion Crack Detection in a Helicopter Gearbox, ARL-TR-2958, U.S. Army Research laboratory, NASA, (2003).

[37] J. Jiang, Z. Chen, W. Zhai, T. Zhang, Y. Li, Vibration characteristics of railway locomotive induced by gear tooth root crack fault under transient conditions, Engineering Failure Analysis, 108 (2020) 104285. 